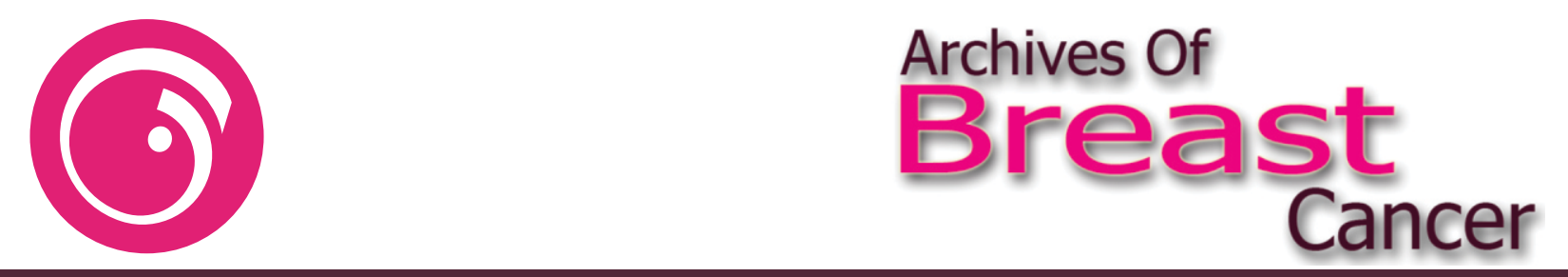

\title{
Oncology Loses a Pioneer
}

\section{Erica Patocskai}

Doctor Robidoux was a full professor in the department of surgery at the University of Montreal and holder of the Scotiabank Chair in Breast Cancer Diagnosis and Treatment from 2000 until recently. He died of cancer at the age of 72 on Saturday, July 25 , surrounded by loved ones.

Doctor Robidoux had an exemplary surgical career and was recognized worldwide for his vision, innovation and dedication in the field of clinical research in breast cancer. The NSABP presented him with the "Distinguished Lifetime Achievement Award" to underline his impeccable commitment to oncology research.

He played a central role in the advances in breast cancer treatments over the past 40 years and treated thousands of women in Quebec with his remarkable expertise and integrity. Besides his outstanding achievements, he was greatly appreciated by his patients, colleagues and research team because of his dedication, great humanity and humility.

He was an exceptional educator, teaching the next generation of surgeons with enthusiasm and patience. He leaves behind a legacy of excellent patient care and a career in research, visionary and unparalleled. He was a cherished colleague who will never be forgotten by those who had the good luck to have know him.

\section{Remy J Salmon}

We are so sad to know of the rapid loss of Professor André Robidux.

After surgical training in the USA, he returned back to Canada, where he rose through the hierarchy, becoming the Medical Director of the Breast Cancer Research Group at the University of Montreal Hospital Center. He was a very well known scientist through his activities in the NSABP, where, as a Francophone, he played an essential role in the transition between Canada and France. If a transatlantic medical cooperation had been possible,
Professor André Robidoux (1948-2020)

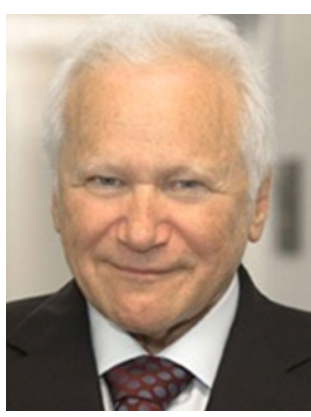

it certainly would have taken place through it.

On a human level, he regularly came to share his experience at conferences in Paris and in the provinces, and it was always a renewed pleasure to discuss with him the progress of medicine and surgery, but also "things" of the world.

He had a benevolent behaviour to all his colleagues, especially towards young people and those training in his team, and his humour, which was clearly visible on his face, taught how to defuse the inevitable tensions in surgical units.

We will miss his friendly and warm presence, his insightful questions and his long-standing friendship. Scientific meetings will not be the same without him.

\section{Michel Alain Danino ${ }^{c}$}

On Saturday 25 July 2020, the breast oncology community lost Professor Andre Robidoux, whose pioneering contributions have shaped several aspects of the battle against breast cancer. It would have been possible to expand on his major academic contribution with 114 publications in peerreviewed journals between 1982 and 2020, 2 books on the history of breast cancer research and his countless invitations as a visiting professor throughout the world.

But the memory that will mark his fellow surgeons is his sparkling, intelligent and mischievous gaze. For us, his colleagues, and his friends, he embodied for all of us a scientific and moral compass. But this probity was with him always associated with kindness.

The population of Dr. Robidoux's laboratory reflected his commitment to the need for international cooperation in scientific discovery and in the dissemination of learning in the breast cancer field. Many languages could be heard in the various labs and offices of Dr. Robidoux's Laboratory. He was appreciated not only for his remarkable knowledge but also for his incredible kindness. But above all, Dr. 
Robidoux lived for his patients. He was listening to their demands for morphologic rehabilitation. We, reconstructive surgeons, always found a rare openness in his person. He was thus one of the first to offer his patients immediate breast reconstructions and skin preservation, he accompanied and gave credit to all breast reconstruction development from cutaneous breast expansion to microsurgical reconstruction by deep inferior epigastric vessels flaps.

Dr. Robidoux's scientific contributions have triggered the ever-expanding horizon of breast cancer research and led to paradigm shifts in our understanding of the genetic origin of this disease. His legacy will endure for generations to come. The plastic surgery community extends its condolences to his wife and family.

\section{Rami Younan ${ }^{d}$}

Named by many of his female patients "Pape"which is the French word for Pope, Dr Andre Robidoux incarnated a figure of Hope for many of them. A native of the small French Canadian village of Sorel, he made his way to the Major Leagues of research on Breast Cancer, the NSABP "National Surgical Breast and Bowel project" organization.

He called the Breast "The Noble Gland" in his discussions with peers, friends or patients as he devoted his professional career and lots of his time to studying and shaping research pertaining to breast cancer.

Always a great story-teller, he always had social talent and tricks in his pocket.

He will be remembered as a Milestone personality in the research on Breast Cancer having gone through breast cancer treatments from the original mutilating Halsted radical mastectomy to the more modern oncoplastic breast techniques, and from completely random systemic treatments to the most precise targeted therapies!

He will be missed by so many...

\section{SaimaHassan ${ }^{e}$}

Dr. Robidoux was a Full Professor in the Department of Surgery at University of Montreal, surgical oncologist at the Centre Hospitalier de l'Université de Montreal (CHUM), and clinical researcher at the Centre de Recherche (CR-CHUM).

Dr. Robidoux dedicated his career to the fight against breast cancer, and his objective was to improve the care for breast cancer patients in
Quebec. Dr. Robidoux helped to bring clinical trials to thousands of breast cancer patients in Montreal. Amongst his many achievements, Dr. Robidoux was a recipient of the Distinguished Investigator Lifetime Achievement Award in 2010, in recognition of his extraordinary commitment to the NSABP and oncology research.

Dr. Robidoux was a visionary and a prolific researcher. He contributed to two paradigm shifts in breast cancer surgery; 1) the change from aggressive, mutilating radical mastectomies to partial mastectomies; and 2) the use of neoadjuvant chemotherapy prior to surgery. He was a thoughtful clinician, a skillful surgeon, a kind mentor, and a warm human being. His passing leaves a huge loss for oncology, his colleagues, friends, and family.

\section{Ahmad Kaviani $^{f}$}

I am one of the last lucky surgeons to be able to work with Professor Robidoux for a while. For the first time, I met him in the summer of 2017 in his small office in the old building of Hotel Dieu in Hospital Montreal. I saw a courteous, kind, and very respectful senior whose great spirit thoroughly impressed me, the professor who was really much greater than his internationally renowned name, Professor Robidoux.

His mastery in the latest clinical studies in breast cancer and his creative and innovative thinking made him always very fascinating and enticing. The extent of his information was not limited to breast cancer or even medicine, and his accurate information on different subjects like the cultural and social backgrounds of different ethnicities all around the world was astonishing.

His ideas to draw a plan for the Archives of Breast Cancer were very instructive and inspiring for me, and I try my best to consider his recommendation in the journal.

I always considered him as a kind and compassionate father. In one sentence, he was a high-ranking and praiseworthy human in all personal and professional fields.

In his mourning, this poem by Rudaki (859-941), the father of Persian poetry, is very befitting by loosing him:

"From the number of two eyes (human beings), one is less,

and many thousands are lost from the wisdom of humankind."

\footnotetext{
${ }^{a}$ Chief of Surgical Oncology Service, CHUM, University of Montreal, Montreal, Canada

${ }^{b}$ Retired Professor of Surgical Oncology, Curie Institute, Paris, France

${ }^{\circ}$ Chief of Plastic and Reconstructive Surgery Service, CHUM, University of Montreal, Montreal, Canada

${ }^{d}$ Associate Professor, Surgical Oncology Service, CHUM, University of Montreal, Montreal, Canada

${ }^{\text {e }}$ Scotiabank Chair in the Diagnosis and Treatment of Breast Cancer, Division of Surgical Oncology, Centre de

Recherche-CHUM, University of Montreal, Montreal, Canada

${ }^{d}$ Editor-in-Chief, Archives of Breast Cancer, Professor of Surgery, Tehran University of Medical Sciences, Tehran, Iran
} 